\title{
O sonho na clínica de casal
}

\author{
Aline Vilhena Lisboa \\ Terezinha Féres-Carneiro \\ Pontifícia Universidade Católica do Rio de Janeiro
}

\begin{abstract}
Resumo
O presente artigo trata a questão do sonho na clínica de casal como recurso técnico de análise, para a elaboração de um material traumático. O sonho é compreendido por Freud como uma atividade intrapsíquica e representante de um conteúdo recalcado sobre um desejo inconsciente. No entanto, sob a teoria de René Kaës acerca da polifonia do sonho, este ganha função compartilhada, cujo processo está presente na dimensão intersubjetiva de um grupo, de uma família e, no caso deste estudo, de um casal. Não só o conteúdo do sonho, mas a atividade realizada pelo pré-consciente do casal aponta dados relevantes numa investigação clínica. $\mathrm{O}$ vínculo conjugal compreende um campo fértil em que atividades psíquicas, como projeções e identificações, aparecem com mais intensidade e são compartilhadas no ato de sonhar. Fragmentos de um caso clínico de casal mostram como o sonho pode ser uma maneira de compreender a intersubjetividade presa ao material recalcado.
\end{abstract}

Palavras-chave: sonho; conteúdo do sonho; trabalho psíquico; clínica de casal.

\begin{abstract}
The dream in couple therapy. This paper deals with the question of the dream in couple therapy, taken as a technical resource for analysis, in the elaboration of a traumatic material. The dream is understood by Freud as an individualized work, representative of repressed content related to a forbidden wish. However, the dream, under the theory of René Kaës about its polyphony, gains a shared function when present in the intersubjective dimension of a group, family and, in the case of this study, of a couple. Not only the dream content, but the work carried out by the pre-conscious as well, reveals relevant data for clinical investigation. The marital link comprises a fertile ground in which psychological activities, such as projections and identifications, appear with more intensity, and are shared in dreaming. Fragments of a couple clinical case show how the dream can be a way of understanding intersubjectivity that is bound to repressed material.
\end{abstract}

Keywords: dream; dream content; psychological work; couple therapy.

A clínica de casal compreende uma investigação e um entendimento do processo psíquico que se estabelece entre duas pessoas, que demandam psicoterapia por apresentarem diferentes tipos de sintomas. Diferente da ideia antiga de aconselhamento e de uma análise individual, a terapia de casal permite pesquisar certas atividades psíquicas que são compartilhadas pelos cônjuges, favorecendo a transformação da conjugalidade e da subjetividade de cada um.

Uma das questões mais interessantes na clínica de casal compreende a busca de sentido das motivações inconscientes que levam duas pessoas à união. Marcados por um pacto inconsciente (Lemaire, 2007), a escolha amorosa do(a) parceiro(a) fomenta, com mais intensidade, algumas atividades psíquicas como as projeções e as identificações que já fazem parte da dinâmica psíquica de cada um. As projeções são mais férteis no vínculo conjugal (Eiguer, 2008; Lemaire, 2007) porque há maior envolvimento emocional, o que favorece a identificação, como um processo de enriquecimento e de transformação da subjetividade dos cônjuges.

Além das duas atividades psíquicas supracitadas, encontramse na conjugalidade a condensação, o deslocamento e a difração, que se revelam com mais intensidade no sonho compartilhado. Apesar da concepção intrapsíquica do sonho em Freud (1900/2001, 1901/2000, 1917/2006, 1920/2006, 1932/2000), o sonho, muito mais que o seu conteúdo, permite compreender as particularidades do funcionamento interpsíquico dos cônjuges e as repercussões deste na intersubjetividade do casal.

A base do sonho na clínica está no acesso ao material inconsciente (Freud, 1900/2001). Além de representar o inconsciente, o sonho é pensado como um recurso clínico para análise do pré-consciente de um grupo, de uma família ou de um casal (Kaës, 2004, 2005a). Neste estudo, o sonho compreende um operador psíquico que orquestra a intersubjetividade do casal, que tem origem na atividade psíquica de cada sujeito. De acordo com Kaës (2005b), a intersubjetividade é o espaço psíquico entre os sujeitos, no qual há as experiências psíquica, 
afetiva e representativa. Neste lugar, os conflitos e as tensões são produzidos, e nele se aplicam e se deslocam as cargas de investimento. Portanto, a intersubjetividade é um espaço de transformação e de atividade psíquica, levando o pré-consciente a operar na reativação de traumas, conflitos e heranças, e servindo como caminho para que as excitações possam ser escoadas, por meio das expressões verbais e não-verbais.

Nessa direção, pode-se dizer que as principais funções do sonho na clínica do casal servem para compreender as atividades psíquicas compartilhadas, que permitirão a passagem do conteúdo recalcado para o manifesto, observando a mensagem endereçada ao outro, no tocante ao conteúdo inconsciente. Desse modo, postula-se que o processo de análise e de elaboração do sonho, construído pelo casal na psicoterapia, permitirá a inscrição de novas representações nas falhas existentes da função do préconsciente do casal.

Por ser também uma atividade compartilhada, o sonho surge como uma mensagem endereçada ao outro, correspondendo àquilo que o outro deixou de sonhar. Na clínica, observase que o sonho, na família e no casal, aparece como uma atividade que exprime a organização e o funcionamento do espaço intersubjetivo, além de permitir a restauração do préconsciente desses grupos. Neste espaço intersubjetivo, os traços de experiências ou lembranças que não puderam ser representados pela psique são apresentados, geralmente, em forma de mensagem criptografada nos sonhos. Para Abraham e Torok (1975/1995), a mensagem criptografada corresponde a um comunicado que passou a ser ilegível devido ao encriptamento de um objeto perdido pelas gerações anteriores. A mensagem carrega consigo uma cripta, um "morto", ou um material denso e de difícil representação para o grupo. Ela é o representante de uma lembrança que havia sido enterrada em algum lugar seguro, à espera de sua ressurreição. Além dessas mensagens mutiladas nos sonhos, as lembranças recalcadas do grupo são barradas no espaço intersubjetivo em forma de censura, negação, recusa ou rejeição, e estas se apresentam como principais meios de defesas.

A questão levantada sobre os sonhos circunscreve dois grandes efeitos deste operador ou atividade psíquica no espaço psíquico do casal. Por um lado, o conteúdo do sonho é analisado como mensagem não elaborada de um material inconsciente e, por outro, as atividades psíquicas envolvidas na elaboração desse material podem facilitar a compreensão do caminho que os psiquismos dos cônjuges fazem para chegar a esse conteúdo.

O sonho pode ser relatado, analisado e elaborado pelo casal durante o percurso de uma psicoterapia. No entanto, nem todos os casais falam de seus sonhos, pois a censura ou a dificuldade de lembrar-se desses pode representar uma resposta defensiva diante de um material recalcado. Pode-se dizer, também, que a análise do sonho na clínica é uma opção tanto do terapeuta como do paciente.

Este estudo teórico, ilustrado por um caso clínico de casal, contempla, inicialmente, as fundamentações freudianas sobre o sonho individual e acrescenta o conceito de Kaës (2004) acerca do "trabalho do sonho" (p. 52). As postulações de Kaës (2004) permitem pensar que, além da análise do sonho individual, o sonho no grupo, mais especificamente no casal, é compartilhado e possibilita entender não só o material inconsciente, como as representações inacabadas sobre as demandas produzidas pelos sintomas.

\section{A teoria freudiana dos sonhos}

No livro “A Interpretação dos sonhos”, Freud (1900/2001) busca compreender o sonho como uma versão fragmentada e incompleta dos pensamentos oníricos, cujo objetivo está em manipular o conteúdo dos pensamentos, condensando, deslocando e substituindo os conteúdos repudiados de um desejo recalcado. No sonho, a fragmentação encontrada representa parte de um pensamento e parte do corpo, significando pontos de reprodução oriundos do material recalcado, de um sentimento reprimido e de um adoecimento somático.

Geralmente desconexos, os sonhos apresentam contradições das mais cruas e violentas formas, desligando-se da racionalidade humana e do mundo exterior, assentando-se num universo desconhecido. Os conteúdos de um sonho apontam para um mundo interno ambivalente pelo qual circulam também, como já dizia Aristóteles, citado por Kaës (2004), os primeiros sinais de uma doença somática antes mesmo que esta se manifeste na vida de vigília.

Do ponto de vista intrapsíquico, o sonho se forma num espaço psíquico fechado. Este espaço permite ao sonho buscar, ao mesmo tempo dentro e fora deste espaço, os elementos para o seu conteúdo, além de procurar na pré-história do sujeito elementos não reconhecidos por ele. Assim, para Freud (1900/2001, 1901/2000), o material do sonho tem uma lógica interna e um sentido oculto.

Na revisão da teoria dos sonhos de 1932, Freud (1932/2000) mostra que o sonho é uma elaboração psíquica de ligação e de transformação, apontando para a importância da fantasia, do desejo e de sua regressão, a fim de que o sonho seja alucinado. Para esse autor, a formação do sonho parte das moções pulsionais, ancoradas no somático, das fantasias de desejo, dos restos diurnos ligados à representação pré-consciente e do inconsciente. $\mathrm{O}$ conteúdo do sonho pode denunciar tanto um sofrimento psíquico quanto um sofrimento somático, por meio de suas formas de apresentação como o sonho esquecido, o sonho com regressões e identificações com um objeto desvitalizado ou "morto".

Nos sonhos esquecidos do sujeito, por exemplo, a resistência ou a censura não traduzem totalmente o sentido do esquecimento, pois o sonho esquecido pode trazer a cripta formada por um conteúdo recalcado censurado. Segundo Abrahan e Torok (1975/1995), a cripta compreende um enquistamento ou o enterro de uma determinada situação vivida como traumática. Um sonho, por exemplo, pode mostrar um conteúdo esquecido, reflexo de uma situação traumática negada ou enterrada. Na clínica de casal estas situações podem aparecer em relatos de casos de morte de entes queridos, acidentes, separações, mudanças geográficas, que tomaram forma de um luto quase patológico, e que tiveram dificuldade de expressão ou de elaboração, por um dos cônjuges ou pelo casal. Desse modo, postula-se que o esquecimento de um sonho não representa somente uma resistência ou uma censura de um desejo inconsciente, como ressalta Freud (1900/2001), mas pode representar a própria cripta, transmitida pelas gerações anteriores, e depositada na intersubjetividade de um casal ou de 
um grupo familiar.

Os sonhos factuais, com repetições de cenas e certo tipo de sequência lógica, mostram uma atividade mais presente dos estímulos somáticos orgânicos e uma superficialidade do mundo interno, que se associa ao próprio eu do sujeito. No entanto, as ações continuadas e, aparentemente, lógicas do sonho estabelecem um contraste com a lógica do inconsciente. Os sonhos impõem ao somático um rebaixamento da atividade psíquica, cujas funções do "isso" e do "supereu" atuam com mais intensidade no acesso ao material inconsciente. $\mathrm{O}$ sonhador, comumente, dá passagem aos materiais constituídos de incógnitas, não só configurando uma operação psíquica, mas um processo somático com a tarefa de proteger o aparelho psíquico das tensões pulsionais excessivas do corpo (Freud, 1900/2001).

Além da função de proteção das tensões psíquicas recentes ou mais arcaicas, para Freud (1900/2001, 1901/2000), o sonho apresenta dois princípios, o da associação e o da conformidade, que independem do tempo e do espaço. O tempo e o espaço constituem um reservatório de traços de memória da história de vida e dos conteúdos de uma herança geracional, habitado em todos os lugares representativos do sujeito (Benghozi, 2009). Assim, em um atendimento clínico, o sujeito pode começar a trazer conteúdos de sonhos e retomar, no espaço representativo do setting analítico, os mesmos conteúdos de um sonho relatado em algumas sessões anteriores, reatualizando, analisando e elaborando certas situações de conflito daquele momento ou de momentos mais remotos. O conteúdo do sonho aponta possibilidades de conhecimento de um material inconsciente, e o trabalho do sonho (Kaës, 2004) permite a ligação, a elaboração e a transformação do sentido de uma demanda e de outras influências adjacentes associadas a esse material. Sob o ponto de vista somático, além de o sonho compreender uma falha, uma falta de objeto representante de um desejo ou um material recalcado, esse garante uma descarga energética e, ao mesmo tempo, uma reativação da permanência no ventre materno (Freud, 1917/2006, 1920/2006).

Embora Freud (1900/2001, 1901/2000) tenha afirmado que o sonho, antes de tudo, é uma comunicação intrapsíquica, a análise do sonho na clínica de família e de casal conduz para uma via de comunicação intersubjetiva, a partir do momento em que o próprio sonho permite supor a existência de lugares compartilhados, que estão articulados também com o social e com as representações culturais. Assim, a análise do sonho em grupo leva o terapeuta ao conhecimento de um contexto cultural, de uma herança arcaica em transmissão, de uma falha da função de continente (o materno) e da qualidade da relação intersubjetiva do sujeito. Já a função do trabalho do sonho em grupo assegura o espaço onírico e a satisfação narcísica dos membros, uma vez que o sonhar junto, ou sonhar com parte do conteúdo do outro, implica incluir o outro no próprio espaço onírico e incluir a si mesmo no sonho do outro. Além de ponto de sustentação para representação de sentido, o sonho revela uma estrutura psíquica que está em ressonância com outras partes externas ao sujeito (Kaës, 2004).

\section{René Kaës e a teoria do sonho compartilhado}

Segundo Kaës (2004), a clínica psicanalítica permite compreender progressivamente de que maneira o espaço intrapsíquico do sonho se articula com os espaços psíquicos de outros sonhadores. Isto quer dizer que, além de o sonho compreender uma produção própria e íntima do sonhador, exprime também e, ao mesmo tempo, a organização e o funcionamento do espaço intersubjetivo de um grupo, de uma família e de um casal. Para esse autor, o sonho compartilhado se elabora no cruzamento de várias fontes, emoções, pensamentos e discursos, e é por meio da identificação que o trabalho do sonho se solidifica. A identificação é a atividade psíquica de ligação mais importante no sonho, e compreende o modo de presença do outro na psique do sujeito. Kaës (2004) ainda demonstra que o sonho é fabricado, em parte e em certas condições, nos lugares nos quais o psiquismo se constitui, ou seja, no espaço psíquico interno no qual se apoia no corpo pulsional, no desejo inconsciente do sonhador, no vínculo com o outro e no espaço psíquico comum e compartilhado. O sonho comum e partilhado produz dois espaços psíquicos, um como lugar de produção de conteúdo próprio e, outro, como espaço de comunicação por meio de um Eu onírico. Diante dessas postulações, o sonho de um casal ganha função compartilhada, uma vez que tem como objetivo a sustentação dos limites da unidade casal, garantindo os termos da aliança, dos pactos e dos contratos inconscientes (Lemaire, 2007).

Kaës $(2005 a, 2005 b)$ apresenta, em suas postulações, a formação do sonho a partir de processos psíquicos comuns, que vêm de processos primários, tais como condensação, deslocamentos, multiplicação, difração, figuração, encenação e dramatização. Todos estes processos primários existentes no sonho servem para agenciar os pensamentos e os vínculos familiares e conjugais. Dessa forma, é possível cogitar que, em casos clínicos de casal, um dos membros pode ter um sonho no lugar do outro, ou que ambos, ainda que em atendimentos separados, podem sonhar, encontrando em seus próprios sonhos traços, fragmentos ou partes da vida em comum com o cônjuge. Desse modo, alguns conteúdos trazidos nos sonhos de casal pertencem à unidade casal, tal qual acontece em outros grupos, como afirma Kaës (2005a, 2005b), e os conteúdos de um atuam no outro e estão, também, associados à vida cotidiana.

A partir da função do sonho no grupo casal, Kaës (2004) demonstra que o mesmo pode atuar na clínica, apontando o retorno do recalcado, da continência de excitações, das representações roteirizadas e dramáticas do aparelho psíquico e dos lugares subjetivos de cada um nesse espaço. Além disso, a função do sonho também é evacuativa, como forma de o sonhador livrar-se do desejo em vez de elaborá-lo, buscando uma vida alucinatória de realização. Nessa direção, enquanto o sonho é, para Freud (1900/2001), uma realização alucinatória de um desejo inconsciente, para Kaës (2004), apresenta como função principal a transformação das experiências traumáticas precoces, a partir do momento em que estas foram compartilhadas por um conjunto. Além dessa função, o sonho serve como holding onírico, de mensagem, de perlaboração e de restauração das funções psíquicas do Eu e do pré-consciente.

O sonho como mensagem é compreendido como aquele que carrega um sentido endereçado a um, ou mais de um, membro do grupo. Essa mensagem é representante de algum material 
recalcado que não pode ser expresso e compreende, na visão de Kaës (2004), traumas infantis carregados de afetos, sentimentos de abandono e violência que, durante a atividade onírica, são revividos pelo sujeito e compartilhados pelo grupo. O objetivo desse processo é colocar em relevo o desejo de reparação e recuperação do prazer do funcionamento mental. No casal, essas mensagens podem estabelecer uma comunicação particular que remete aos tempos de origem da família de cada um, na qual alguns traços não encontraram, até então, formulações necessárias.

Nesse sentido, o trabalho do sonho no casal apresenta um caminho de análise dos conteúdos manifestos e latentes diante de um material inconsciente compartilhado. O sonho cumpre funções de continente, barreira, proteção e filtro, além de possuir uma função reparadora na clínica. A análise dos sonhos na clínica de casal tem como proposta a observação da atividade do préconsciente, cuja função é também apontar sentidos e marcar o lugar do outro na relação, sob as variadas formas de acolhimento, contenção, ligação e transformação ou interpretação do conteúdo trazido pelo casal (Kaës, 2004).

\section{A dimensão da conjugalidade e a clínica de casal}

A conjugalidade é compreendida, de acordo com Magalhães (2009), como um entrelaçamento de dois "eus" que caminham em direção a uma identidade compartilhada. O casal tenta construir uma nova identidade, a partir de um projeto conjugal, de um futuro familiar para marcar a continuidade geracional. O casal conjugal se constitui a partir do modelo parental, trazido pela herança geracional e, como grupo, é lugar no qual o paradoxo fusão-separação atua constantemente num movimento contínuo de representações e elaborações.

Antes da formação do casal, existe uma história anterior ao laço conjugal que ocupa um lugar no vínculo. As heranças deixadas pelas figuras parentais são reatualizadas e ocupam o imaginário e a fantasia do novo casal. Em certos casos, a reatualização de parte de uma história familiar aparece nos sonhos como peça de um grande quebra-cabeça.

As atividades psíquicas existentes na intersubjetividade do casal refletem nas suas complexas relações com as circunstâncias dos traumas e dos conflitos apresentados por meio dos sintomas. Desse modo, as atividades como a projeção e a identificação aparecem com mais intensidade no sonho e interferem na promoção de saúde, podendo favorecer o desenvolvimento de doenças do casal.

Para Magalhães (2009), a conjugalidade pode ser considerada uma dimensão privilegiada no processo de recriação do eu, quando a estabilidade do vínculo corresponde à manutenção do estado amoroso, em razão do investimento realizado pelos parceiros por ocasião do engajamento conjugal. Da mesma maneira, para Puget e Berenstein (1993), “a criação de um objeto casal compartilhado será resultante inédita da conjugação dos representantes de cada um, onde a posição esposa-esposo adquire um conteúdo significativo" (p. 6). A conjugalidade tem o seu valor estruturante antecedido pelos ideais de conjugalidade, que podem sofrer interferência da fantasmática do casal parental mais próximo, os pais.

A história geracional de um casal pode promover conflitos sucessivos, na medida em que traumas ou conteúdos censurados não puderam ser simbolizados devidamente e não tiveram um lugar de expressão. Na história do casal, há acontecimentos significativos que são permeados pelos legados herdados. $\mathrm{O}$ nascimento do filho, a relação mãe-bebê, a integração da função paterna podem promover a eclosão de conflitos, levando o casal a reorganizar, ou não, sua relação vincular. As situações de conflito e trauma no casal são decorrentes da qualidade dos vínculos estabelecidos. Os vínculos têm como função unir, atar os laços libidinais e afetivos, fortalecendo a intersubjetividade do casal contra os fantasmas herdados. O tecido vincular de um casal serve para definir o mundo intersubjetivo como diferente do intrasubjetivo, posicionando o sujeito diante do outro por duas vias de compreensão: uma, pelos aspectos mais inconscientes do vínculo, e outra, pelos aspectos intersubjetivos propriamente ditos, configurados pelas alianças e pactos conscientes, préconscientes e inconscientes (Eiguer, 2008; Lemaire, 2007; Puget \& Berenstein, 1993).

Nicolló (1995) ressalta, ainda, que na constituição do casal há um espaço de oscilação contínua, em que cada cônjuge é uma extensão do outro, ao mesmo tempo em que é diferenciado do outro. Muitas patologias podem emergir diante da falta de diferenciação no casal. Na clínica, por meio dos sonhos, o material pode pertencer a um, mas é sonhado pelo outro. $\mathrm{O}$ sonho pode oportunizar a observação da tramitação intersubjetiva dos conteúdos de um para o outro, pois como diz essa autora, a função idealizadora da escolha amorosa faz emergir os estados regressivos e os aspectos funcionais mais primitivos. Embora tenha uma aparente estrutura psíquica diática, o casal possui uma ligação com muitos outros objetos, sejam reais ou imaginados, que transbordam do psiquismo individual e se confundem com o do outro.

Postula-se que, na trama intersubjetiva do casal, vão-se entrelaçando algumas atividades psíquicas que provocam diferentes efeitos na subjetividade de cada um. Além da herança psíquica parental e ancestral, desde o nascimento, as primeiras impressões do meio externo são sedimentadas e reatualizadas na conjugalidade, ao longo do tempo. Desse modo, Kaës (2004) revela que a identificação projetiva é um conceito decisivo para articular as fronteiras interna e externa de um espaço psíquico.

Num casal, o reconhecimento de um conflito se fundamenta na interpretação e na interdiscursividade que ambos dão às suas próprias angústias. Assim, a projeção tem como função expulsar os desejos, os sentimentos e até os objetos perdidos, enlutados ou internalizados parcialmente (Abrahan \& Torok, 1975/1995), na tentativa de transformar os impasses e as repetições herdadas pelos cônjuges, estabelecendo uma interseção entre o que é de um e o que é do vínculo conjugal. A constituição do aparelho pré-consciente do casal fica comprometida, a partir do momento em que este for devidamente destituído ou incapaz de nomear, significar e interpretar as necessidades de um e de outro (Kaës, 2005b). Em atendimentos clínicos, observa-se certa dificuldade de compreensão quando um parceiro adoece. Percebe-se que a fragilidade de um cônjuge pode comprometer o futuro do projeto familiar, uma vez que a conjugalidade se torna campo fértil para fantasias e fantasmas perturbadores (Lemaire, 2007).

As fantasias carregam fantasmas que se estabelecem como 
sombra, dificultando as representações, que por sua vez estão comprometidas com objetos póstumos (Abraham \& Torok, 1975/1995). Os objetos póstumos, segundo Torok (1968/1995), vêm pela introjeção, que compreende uma maneira de o sujeito entender a morte não elaborada de um de seus genitores. $\mathrm{Ou}$ seja, o sujeito, após a morte de um dos pais, tenta adoecer e se curar, procurando, com um sentido paradoxal, compreender e representar com o seu conflito aquilo que os pais não conseguiram entender sobre os seus próprios conflitos. Desse modo, um objeto póstumo encarna no fantasma, que vem habitar o pré-consciente do casal. Os sentimentos estranhos e ruins podem ser compreendidos como lacunas deixadas pelo outro por causa destes fantasmas.

A história de um casal pode trazer elementos traumáticos anteriores, que se atualizam nas projeções e nas identificações constituintes da conjugalidade. A seguir, a história do casal Silveira mostra que o sonho pode denunciar um sofrimento psíquico, abafado durante anos. E este sonho compartilhado, na clínica, serve como meio de elaboração do material recalcado.

\section{Fragmentos de um caso clínico ${ }^{1}$ - O sonho com- partilhado do casal como via de elaboração de um material recalcado}

A história do casal Silveira² é merecedora da atenção daqueles que fazem da clínica um lugar também de estudos e pesquisa, e compreende um caso bem sucedido de terapia de casal. A particularidade da psicoterapia deste caso foi o conteúdo dos sonhos relatados e a interpretação realizada pelo casal e pela psicoterapeuta ${ }^{3}$ durante algumas sessões.

Pedro e Ana formam um casal jovem, na faixa dos 30 anos e, à época do atendimento psicoterápico, tinham um pouco mais de uma década de casamento. Ambos tinham formação superior e estavam com as carreiras profissionais encaminhadas. Eles realizaram um percurso de quase dois anos de terapia e a natureza da transferência na psicoterapia se embasava em sentimentos e expressões que apontavam um pedido de proteção e amparo pelos mesmos. Ana procurou, primeiramente, por terapia de casal, queixando-se de discussões rotineiras com o marido. Pedro concordou em participar e aderiu às queixas de Ana, durante $o$ primeiro momento da terapia. Entretanto, no relatar dos fatos, a principal questão trazida pelo casal foi o desejo de ter um filho.

Após 10 anos de união, Pedro e Ana pensavam em um filho, mas as expectativas depositadas em torno deste projeto encontraram nos sintomas de ansiedade e de insegurança de ambos, e de irritação de Ana com Pedro, um mal-estar e uma limitação para prosseguir com a conversa sobre tal projeto. Durante os momentos seguintes da terapia, foi observado por eles que a continuidade do vínculo conjugal estava em risco, tendo em vista a dificuldade do casal de entender como lidavam com este conjunto de circunstâncias conflituosas e com os sentimentos de ambos. As queixas foram além de situações do cotidiano e mostraram algumas ideias associadas a uma fantasia ainda não elucidada. Ana se queixava da sensação de mal-estar diante de Pedro. Em uma sessão, ela havia relatado que não sabia explicar o porquê de Pedro a fazer sentir "coisas sem explicação", provocando nela uma sensação ruim. Segundo Ana, esta sensação não era fruto de uma discussão, mas do silêncio de Pedro diante de suas argumentações sobre os assuntos que provocavam discussões, às vezes, fervorosas. Na verdade, Ana observava que estas colocações convocavam Pedro a demonstrar afeto, o que, segundo ela, não acontecia, pois ele se mostrava indiferente diante dos sentimentos dela.

Embora o projeto de ter um filho fosse do casal, ao iniciar a conversa sobre o mesmo, o silêncio e a distância de Pedro causavam, em Ana, sensações ruins; situação que se repetiu no setting analítico. Sentimentos ambivalentes apareceram na forma de insegurança de ambos e na fala trêmula de Pedro, principalmente. Ana demonstrava o desejo de ter um filho, mas vivenciava uma ansiedade nas tentativas de engravidar. A fantasia de não conseguir engravidar passou a ter forma diante das tentativas fracassadas. A vontade de Pedro de ter filho, por sua vez, despertava uma angústia silenciosa e duradoura. Eles passaram a investir em outros projetos, como o da casa própria, a fim de adiar o projeto de ter um filho e evitar a ansiedade e a angústia que circulavam neste investimento.

A terapia de casal pode oferecer aos cônjuges a oportunidade de conhecimento da própria história, uma vez que também tem como objetivo obter informação dos sujeitos para melhor trabalhar com os mesmos. Assim, havia algo a ser esclarecido acerca da representação de ter filho ou de ter sido filho na vida do casal. O filho, de maneira ambivalente, surgia como uma personagem, que faria reviver assuntos ainda não elaborados pelo casal. A partir da demanda do casal, lançamos a questão norteadora deste caso: quais seriam estes assuntos não elaborados que resultavam em conflitos cotidianos e acabavam incidindo sobre o projeto de ter filho?

Ao longo do processo psicoterápico, o desejo de ter um filho passou a ter pouco investimento, pois a fantasia construída em relação à dificuldade de gerá-lo estava circulando em toda a capacidade de elaboração do casal. Em meio aos sentimentos ambivalentes, o casal realizava os exames pré-natais necessários, que mostravam condições saudáveis para a gravidez. No entanto, as tentativas malsucedidas foram gerando medo e angústia, que se potencializaram e encontraram uma forma de expressão em certas somatizações, como o refluxo gástrico de Pedro e as dores de cabeça de Ana.

Com a intenção de investigar a história familiar, decidiuse pela aplicação do genograma projetivo, que se constitui num recurso gráfico construído pelos clientes, possibilitando a inclusão de dados mais subjetivos de análise da história parental e ancestral dos mesmos (Cerveny \& Almeida Prado, 2008). Na sessão seguinte à confecção do genograma, após breve exposição de Ana sobre sua tonteira, ela iniciou um relato de sonho recente, com um primo materno, com quem não tinha contato há muito tempo. A cena do sonho mostrava o silêncio do primo e de Ana sobre algo. O sonho gerava em Ana ansiedade e dúvida sobre o motivo pelo qual sonhara com o primo. Nesta mesma sessão, foi perguntado para Pedro sobre a lembrança de algum sonho. O mesmo disse que dificilmente lembrava-se de algum, a não ser quando sonhava com os pais, sonhos geralmente repetitivos, em situações do cotidiano.

Nos sonhos de ambos, as cenas mostravam um silêncio existente diante de circunstâncias não claras e uma repetição de fatos, talvez encobridores de um silêncio sobre um material 
recalcado. Esses silêncios foram considerados os representantes do material censurado, esquecido, com o qual ambos têm dificuldade de entrar em contato e de elaborar. Nessa direção, a interpretação do sonho do casal constituía-se numa tentativa de compreender o sentido de seus conteúdos na formação da fantasia de fracasso materno e paterno, partilhado e sustentado por Ana e Pedro. O sonho ainda produzia sentimentos ambivalentes em ambos e o trabalho deste representou um meio de o casal ligar e interpretar lembranças e fatos não superados.

Havia fatos significativos, na história anterior de Pedro e Ana, que interpelavam o projeto de vida do casal. Ana era filha única, cuja mãe, na ocasião de sua gravidez, não queria ter filhos. Segundo ela, sua mãe fala até hoje, em momentos de brigas e discussões, que o fato de ter tido filho atrapalhou seu desenvolvimento profissional. Ana sentia muita culpa em relação ao fracasso profissional da mãe. Os relatos de Ana traziam sentimentos de raiva e mágoa, que por sua vez eram projetados no vínculo com o marido. Sobre Ana, pode-se pensar que o desejo de ter filho reatualizava os sentimentos ambivalentes de amor e ódio, e a culpa em relação à mãe. A mãe de Ana teve uma relação difícil com a gravidez e com os primeiros cuidados com a filha recém-nascida. Seu pai assumiu este lugar e era visto como um homem com atitudes mais acolhedoras e maternas. A identificação com o pai sustentava parte dos sentimentos amorosos com o marido. Havia, também, na história materna, casos de parentes com quadros de psicose e de transtorno obsessivo compulsivo, o que configurava um medo real de Ana sobre a personalidade do filho.

A família de Pedro tinha um enredo bem diferente. Ele era o filho do meio de uma família com três filhos e descrevia-a como uma família tranquila. No início de sua puberdade, após mudar-se para morar em outro estado do país, ele se distanciou de amigos e parentes. Esse momento compreendeu um primeiro reconhecimento de Pedro sobre o seu estado de desamparo e solidão. Além do episódio da mudança, o maior acontecimento na sua história de vida ocorreu quando seu pai faleceu, aos 52 anos, em consequência de um câncer no cérebro. À época, Pedro tinha 17 anos, o que fez dele um adulto mais cedo, administrando a casa e cuidando do irmão mais novo e do mais velho, que se envolvia com drogas e em atividades suspeitas. Oito anos depois, aos 25 anos de idade, Pedro perdeu a mãe (à época, com 57 anos), que estava com câncer no pulmão, e assumiu a responsabilidade pela casa e os cuidados para com os irmãos. Seus relatos reforçaram as queixas de isolamento e ressaltaram os sentimentos de abandono. O dado novo foi a mágoa que sentia pela mãe, por não orientá-lo em momentos difíceis. De um modo geral, segundo Pedro, ele e seus pais mantinham um contato mais formal, com deficiência de afeto, carinho e contato físico.

No curso das sessões seguintes, puderam ser observadas as primeiras associações de Ana e Pedro em relação ao medo de ter filho. Ana argumentou que o medo de ter filho estaria associado a não saber cuidar dele. De modo comovente, Pedro relatou a respeito de seu medo de morrer cedo, como os seus pais, e, por isso, não participar da vida do filho e dar-lhe a assistência necessária.

Pode-se dizer que o sonho do casal foi compartilhado, a partir do momento em que ambos apresentaram uma cena em comum, ou seja, a representação dos pais em suas vidas e o silêncio diante das mágoas e sentimentos de abandono não superados anteriormente. Contar o sonho de cada um favoreceu a análise de dados comuns, que interferiam no campo intersubjetivo. $\mathrm{O}$ fato de ambos terem medo de sustentar (psiquicamente) um filho, reatualizou os sentimentos de abandono e de mágoa vivenciados outrora com os pais. O sonho, com cenas factuais de Pedro, aparentemente, mostrava uma escassez de afeto, o que permitiu observar uma repetição na vinculação com a esposa Ana. O sentimento de abandono aparece no silêncio de Pedro, que provoca em Ana sensações ruins. Mais tarde, esse sentimento foi reconhecido por ambos e observado por meio de falas embargadas e trêmulas. Sonhar com os próprios pais reforça a ideia da perda não superada. As excitações provenientes destes fatos ocorridos com Ana e Pedro circulavam na fantasia de ambos "de não conseguirem ter filho", comprometendo o próprio projeto. Os sentimentos de abandono, perda, rejeição e culpa receberam destino em palavras e articulações, desvelando a mensagem inacabada no conteúdo dos sonhos e compreendendo o sentido do endereçamento da mesma, por meio do silêncio de ambos.

O sonho com o primo materno levou Ana a associar a sua situação de conflito e iminente separação com a conjuntura da separação dolorosa, sofrida pelo primo, naquela época. Ana identificava-se com a situação do primo, uma vez que a figura do mesmo representava a condensação de seus conflitos com Pedro.

O sonho do casal foi compreendido por ambos os cônjuges, à medida que perceberam, na figura do filho, o caminho necessário para a elaboração do material recalcado. Embora os sonhos tenham partido das atividades psíquicas de cada um, o trabalho de associação possibilitou o compartilhamento dos problemas projetados no vínculo, que estavam sendo sustentados pela fantasia e herança do fracasso materno e paterno. O fantasma dos pais de Pedro encarnavam nos sentimentos de vazio e solidão de Ana, mostrando uma ligação a um objeto póstumo, resultado de um luto falho do marido pela perda dos pais. O efeito do fantasma se estendia na conjugalidade, minando, gradativamente, os investimentos libidinais em projetos de vida, neste caso, de uma gravidez.

O potencial psíquico do casal Silveira permitiu que, em análise, o sonho pudesse ser um recurso ativo na recuperação de dados significativos da história anterior, sem que a censura e a resistência engessassem o processo. Pedro e Ana, ao final do processo terapêutico, conseguiram vencer o medo de uma gravidez fracassada. A psicoterapia encerrou-se com o pedido de ambos para uma análise individual. Tempos depois, Pedro ligou e anunciou o nascimento de sua filha, dizendo que Priscila nascera com muita saúde e estava sendo bem cuidada e amparada pelos pais.

\section{Considerações Finais}

O sonho tem sido investigado por mais de um século pela Psicanálise e ainda é considerado um tema bastante intrigante, quando se trata de sua dinâmica, conteúdo, significado e de seu endereçamento e compartilhamento. Apesar de ter sido considerada uma atividade intrapsíquica por Freud (1900/2001, 
1901/2000, 1917/2006, 1920/2006, 1932/2000), o sonho corresponde também, na concepção de Kaës (2004, 2005a, 2005b), a uma atividade intersubjetiva de um grupo, de uma família e de um casal.

A atividade do sonho opera não só na dinâmica intrapsíquica do sujeito como orquestra toda a atividade do pré-consciente compartilhada por um casal, de maneira que juntos possam ligar, associar, interpretar e transformar um conteúdo recalcado. Apesar de apontar um desejo inconsciente, com uma lógica intrapsíquica própria, a concepção de trabalho do sonho trazida por Kaës (2004, 2005a, 2005b) indica um importante recurso na prática clínica com grupos, famílias e casais, a fim de que seja permitida a passagem do conteúdo recalcado para o conteúdo manifesto, consciente, por meio do trabalho conjugado de associação, análise e interpretação. Acredita-se que o trabalho de elaboração permitido pelo sonho compartilhado possibilita a reconfiguração de heranças, na tentativa de dar destino a elementos falhos e existentes que circulam no pré-consciente do casal.

Na clínica, o relato e a análise do sonho do casal favorecem a atividade de expressão e de reorganização do espaço intersubjetivo. Neste espaço, as lembranças de experiências que não puderam ser representadas pelos mesmos são apresentadas, geralmente, em forma de mensagem criptografada nos sonhos. No caso dos Silveira, sua história trouxe elementos traumáticos anteriores que se atualizaram nas projeções e nas identificações, que incidiram na conjugalidade. A análise dos sonhos na clínica de casal, apresentada neste estudo, permitiu que fossem observadas a recordação e a elaboração de um material traumático recalcado, simultaneamente projetado e compartilhado no vínculo conjugal. Trabalhar com a análise dos sonhos compartilhados compreende uma maneira de viabilizar a construção de uma identidade conjugal.

A análise do sonho do casal Silveira teve o propósito de reconfigurar, psiquicamente, as fraturas ocasionadas pelo trauma da morte dos pais de Pedro e do sentimento de abandono e culpa de Ana em relação à mãe. O impasse gerado entre o desejo de ter filho e a fantasia de não conseguir criá-lo compunham o pano de fundo de um cenário de conflitos cotidianos, vivido pelo casal. A falta de conhecimento e de elaboração desse impasse causava ansiedade e angústia, efeitos que minavam o investimento do casal em si mesmo, a ponto de dificultar uma gravidez em meio a condições biológicas saudáveis de ambos.

Kaës (2004) reforça a ideia do sonho como continente psíquico para o bem-estar do funcionamento mental, como foi observado no caso de Pedro e Ana, ao afirmar que "sonhamos aquilo que não podemos dizer” (p. 98). Desse modo, pode-se considerar que a função de ligação e de transformação do sonho no casal permite que ele sirva de continente psíquico para que as projeções dos cônjuges aconteçam de forma mais saudável, elaborando materiais que possam causar sofrimento. Além disso, o sonho pode ser concebido como um processo interpsíquico que mantém a ligação necessária entre os sujeitos, a fim de que se possa dar contorno à unidade casal, garantindo o vínculo e protegendo os seus ideais.

\section{Referências}

Abraham, N., \& Torok, M. (1995). "O objeto perdido-ego", notações sobre a identificação endocrípta. In N. Abraham \& M. Torok (Orgs.), A casca e o núcleo (pp. 277-296). São Paulo: Escuta. (Texto original publicado em 1975)

Benghozi, P. (2009). A traição como herança: desconstrução e neocontinente narrativo - tópica de um apoio transcontinente. In I. C. Gomes (Org.), Clínica psicanalítica de casal e família (pp. 3-24). São Paulo: Santos.

Cerveny, M. O., \& Almeida Prado, A. E. F. (2008). Genograma: um desatador de Nós na construção de conhecimento. In R. M. Macedo (Org.), Terapia Família no Brasil na última década (pp. 128-131). São Paulo: Rocca.

Eiguer, A. (2008). Jamais moi sans toi. Paris: Dunod.

Freud, S. (2001). A interpretação dos sonhos (Edição Comemorativa). Rio de Janeiro: Imago. (Texto original publicado em 1900)

Freud, S. (2000). Sobre os sonhos. In S. Freud, Obras psicológicas completas (Vol. 5) [CD-ROM]. Rio de Janeiro: Imago. (Texto original publicado em 1901)

Freud, S. (2006). Suplementos metapsicológicos à teoria dos sonhos. In S. Freud Obras psicológicas completas de Sigmund Freud - escritos sobre a Psicologia do inconsciente (Vol. 2, pp. 75-98). Rio de Janeiro: Imago. (Texto original publicado em 1917)

Freud, S. (2006). Além do princípio do prazer. In S. Freud, Obras psicológicas completas de Sigmund Freud - escritos sobre a Psicologia do inconsciente (Vol. 2, pp. 123-182). Rio de Janeiro: Imago. (Texto original publicado em 1920)

Freud, S. (2000). Revisão da teoria dos sonhos - Conferência XXIV. In S. Freud, Obras psicológicas completas (Vol. 22) [CD-ROM]. Rio de Janeiro: Imago. (Texto original publicado em 1932)

Kaës, R. (2004). A polifonia do sonho. São Paulo: Idéias e Letras.

Kaës, R. (2005a). La parole et le lien: processus associatifs et travail psychique dans les groupes. Paris: Dunod.

Kaës, R. (2005b). Os espaços psíquicos comuns e partilhados: transmissão e negativo. São Paulo: Casa do Psicólogo.

Lemaire, J. G. (2007). Croire, se fier, se lier: la constituition du lien amoureux. Dialogue, 178, 55-67.

Magalhães, A. S. (2009). Conjugalidade e parentalidade na clínica com famílias In T. Féres-Carneiro (Org.), Casal e família: permanências e rupturas (pp. 205-217). São Paulo: Casa do Psicólogo.

Nicolló, A. (1995). O modelo psicanalítico de funcionamento do casal. In M. Andolfi, C. Angelo, \& C. Saccu (Orgs.), O casal em crise (pp. 75-90). São Paulo: Sumus.

Puget, J., \& Berenstein, I. (1993). Psicanálise do casal. Porto Alegre: Artes Médicas.

Torok, M. (1995). Doença do luto e fantasia do cadáver saboroso. In N. Abraham \& M. Torok (Orgs.), A casca e o núcleo (pp. 215-35). São Paulo: Escuta. (Texto original publicado em 1968) 
1. Os membros do casal assinaram o Termo de Consentimento Livre e Esclarecido e, após terem lido o texto do manuscrito, autorizaram sua publicação.

2. O sobrenome e os nomes dos cônjuges são fictícios, preservando-se a identidade dos mesmos.

3. Caso atendido pela primeira autora deste artigo.

Aline Vilhena Lisboa, mestre em Psicologia Clínica pela Pontifícia Universidade Católica do Rio de Janeiro, é doutoranda em Psicologia Clínica pela mesma instituição e membro pesquisadora do Núcleo Interdisciplinar de Investigação Psicossomática da Universidade Federal de Juiz de Fora (NUIPSO/UFJF). Endereço para correspondência: Rua Joaquim Vicente Guedes, 406, ap. 401, Cruzeiro do Sul, Juiz de Fora-MG, CEP: 36030-120. Telefone/Fax: (32) 3236-6300. E-mail: alinevlisboa@ig.com.br

Terezinha Féres-Carneiro, pós-doutora em Psicoterapia de Casal e Família pela Universidade de Paris V, França, é professora titular do Departamento de Psicologia da Pontifícia Universidade Católica do Rio de Janeiro e Bolsista de Produtividade em Pesquisa do CNPq. E-mail: teferca@puc-rio.br 